\title{
International Experiences and the Implications for the Success of Engineering Programs
}

\author{
Claudio R. Brito \\ President of IEEE Education Society \\ President of COPEC - Science and \\ Education Research Organization \\ Santos, Brazil \\ drbrito@copec.eu \\ Rosa M. Vasconcelos \\ Board of Governors of IEEE Education \\ Society \\ President of Pedagogic Council of \\ Engineering College at University of \\ Minho \\ Guimarães, Portugal \\ rosa@det.uminho.pt
}

\author{
Melany M. Ciampi \\ President of WCSEIT - World \\ Organization on Systems Engineering \\ and Information Technology \\ Secretary of IEEE Education Society \\ Braga, Portugal \\ drciampi@copec.eu \\ Luis A. Amaral \\ President of CCG-Computer Graphics \\ Centre \\ Professor of Information Systems \\ Department at University of Minho \\ Guimarães, Portugal \\ amaral@dsi.uminho.pt
}

\author{
Henrique D. Santos \\ Vice President for Conferences of IEEE \\ Education Society \\ Director of Information Systems \\ Department at University of Minho \\ Guimarães, Portugal \\ hsantos@dsi.uminho.pt \\ Victor A. Barros \\ Executive Secretary of COPEC - Science \\ and Education Research Organization \\ Researcher of Information Systems \\ Department at University of Minho \\ Jataí, Brazil \\ victor@copec.eu
}

\begin{abstract}
The working midst has become challenging due to the multicultural environment and the need of skills such as cultural understanding, are very important in the formation of an engineer. It has been like this for many years however, now more than ever. So, for engineering schools, internationalization has become, on top of others, another demand for the accomplishment of a good program. It became necessary to provide international academic experience for the students. For this reason, internationalization is now a strategy to raise the quality of courses and as another result of these efforts, to raise the engineering students' retention rate along the program. The goal of this paper is to present and discuss the internationalization process of a University's engineering school, with the objective of making the program more attractive and promoting the double diploma in order to higher the quality of the programs.
\end{abstract}

Keywords-multiculturalism, retention, double diploma, internationalization

\section{INTRODUCTION}

The success of a program, no matter what the field is, depends on its capability to form professionals who are capable to succeed in their careers. It is the key element that entices new students to enroll in the program. A University degree is very important and necessary for the promotion of citizenship and the construction of a better life for future generations.

The consequences of a good program, mainly in engineering, can leverage many facets of human beings. To start with, a good engineer can contribute significantly to the welfare of local community, in which s/he is working and living. However, in the current global community, where people are living having a good higher education is not enough. The world has become challenging due to the multicultural environment and the need of skills, such as cultural understanding, are very important in the formation of an engineer.
Taking this world scenario into account, engineering schools have, on top of other demands, another demand for the accomplishment of a good program. It became necessary to provide international academic experiences for students along the program. It is considered a strategic element to enhance the quality of programs, as well as an effort to raise the engineering students retention rate along the years.

Although it is not a new trend, mainly in the engineering field where engineers have always had mobility experiences, many engineering schools have realized that mobility collaborates with the necessary actions to revise their strategies for the development and updating of their courses as well. Offering an international experience in an engineering program enables the students and graduates to achieve the essential academic and professional skills, allowing them to enter and stay in the present challenging, mutant and multicultural work market of a truly global world. It adds value to the training of the new professional and to the diploma offered by the university.

Internationalization is taken as a current need to bring the intercultural and international perspective to higher education training.

In order to implement a fully successful process of internationalization at graduation level it must involve an active and responsible engagement of the academic community in global networks and partnerships.

Under this perspective the inter institutional international cooperation, in its essence, implies some fundamental conditions such as:

- to recognize the existence of people, protagonists of cooperation;

- all participants in the process should be involved and committed to the forms of cooperation, in accordance with the availability of available human and financial resources; 
- the goals of cooperation have to be clearly defined and consistent with implementation strategies;

- projects should be included in the strategic development plans of the institutions, optimizing the benefits and improving the partners development levels;

- the activities must be specifically established, respecting previously defined schedules and budgets;

- and, finally, it is important to establish mechanisms directed to the development and evaluation of the cooperation actions [1].

The establishment of internationalization strategies requires the observation of some peculiarities that may limit the area of activity, such as:

- restrictions in terms of geographical location of partner universities;

- existence of language barriers;

- $\quad$ areas of excellence in teaching or research, as well as the level of development of the country where the institution is located;

- However, Europe is one of the favorite destinies for most regions. Because of its history, diversity of regions and languages besides the glamour of old world.

In several ways, the internationalization of higher education strengthens its academic programs but also benefits the countries economy, enhances cultural understanding, and ultimately leads to a better future for the globalized world in which we live and will live [2].

The objective of the proposed project is to make programs more attractive and to promote the double diploma in order to enhance their quality.

This particular project has been developed for a private university, which sees internationalization as an opportunity, not only to increase the quality of its programs, but also to attract more brilliant students aiming the further expansion of scientific research that is now modest.

\section{World Work Market AND ENGINEERING PEDAGOGY}

Several studies close to enterprises show that, on average, $40 \%$ of young graduates worldwide do not have the skills to make appropriate decisions outside the university environment in which they have spent 4 or 5 years.

The problem may be because of the different environments: on one hand, the highly structured environment of educational programs, and on the other hand, the changing, dynamic and challenging modern working environment.

The academic environment, by its structuring characteristics needs to have schedules and study guides, and followed by the students for the construction of the knowledge, which should be taken seriously. However, in the workplace, as professionals the success implies their capability to be creative, innovative and adaptable. In other words, newly trained professionals are losing the skills needed to adapt to the workplace, where the tasks to be performed cannot simply be learned from a textbook during a semester. Thus, it can be said that the so-called "soft" skills, in turn, are obtained as a derivative of how students actually learn, but not exactly what they learn.

The way to improve this transition from the academic environment to the work environment might be obtained by modernizing the students' curriculum. Nowadays, there are harsh criticisms to teaching methods that lead the professional to a long period of adaptation. However, there has to be a starting point that can start a new academic journey, which allows students to acquire the necessary skills for a short adaptation period to the job market. It can be achieved by traditional general training of engineers that enables them to face changes more quickly [3].

Another important aspect that should be taken into account is that governments are investing in their education systems from basic education to university. Both public and private educational institutions are those that are able to train professionals ready to collaborate to build a better future. However, it is indisputable that there is no better institution than universities to offer such opportunities, in collaboration with companies that can offer valuable internships.

Lately, it is noticeable that the global growth of transnational education, in the last decades has been one of the defining points of international education and has had significant impact on both host institutions and what can be called provider institutions, or partner institutions.

One of the most notable features of this development has been its global perspective nature, with new hosting and providing countries emerging. This has resulted in a much greater choice and increased access to an international education program for students, but also in greater complexity.

Summarizing Nations must train their citizens and also to try to attract highly skilled professionals in order to keep being competitive in a global scale and assure a future for humanity.

\section{ASPECTS OF INTERNATIONALIZATION}

Internationalization is taken as a current need to bring the intercultural and international perspective to higher education training. International education is complex, multi-dimensional and interdisciplinary.

Internationalization has as positive aspects the improvement of academic quality, besides the enlargement of opportunities for students. For host institutions, some of the benefits of this internationalization are in addition to increasing revenue, the acquisition of future intelligent professionals that will contribute to the future of the country.

In every respect, including ratio of international students, franchiser of academic programs to foreign providers or quality guarantors, Western developed countries gain the main financial benefits [4].

Other benefits of internationalization are: diversified and intelligent learning for the benefit of students, the University 
and the country. In addition, as mentioned earlier, internationalization has the potential to change the lives of students as it helps to produce graduates who are internationally knowledgeable and culturally sensitive.

Regarding students' mobility, it allows them to experience a different environment, in such a way that they can understand the connections between the local environment in which they live and the global environment. [5].

The quality insurance is an issue of great importance. Low standard international higher education programs are not accepted. Providers, programs, credits and qualifications must be recognized at national and international level. Other issues related to the internationalization of education, which deserve attention, are the registration, licensing and recognition by the sending or the receiving countries. Many countries do not have the rigid systems to register or assess out of country providers, making monitoring of their activities difficult. Besides, it is difficult to standardize and maintain the quality of the academic experience of students studying abroad.

\section{The Proposed Project}

To understand the relevance between school disciplines and how a career building journey takes place, it is helpful for young people to understand how work dynamics work. The ability to make connections between one skill set and another set of skills is the basis of the development of the future engineer's career plan. This is what young graduates will do for the rest of their lives, as they progress in their own careers. Developing a successful career requires that they continually ask themselves, "Where can I go from here with my current skills? - Given my vision and skill set today, what additional skills will increase my ability to achieve my vision? " The role of the engineering school also includes helping them to initiate this process of questioning, already during their training, hence the importance of a good engineering course.

Engineering courses are actually full of important core subjects which enable the students to develop their professional careers as engineers, however, it is necessary to innovate and find ways to embed the curricula with important topics to fulfill the new requirements of what is called "global world trends".

Engineering skills are internationally portable, leading to international mobility, which makes the profession extremely interesting. Intercultural skills, knowledge of languages and cultural prejudice management are also very important, because opportunities are extra boundaries and it is important to be able to adapt to any different cultural environment [6].

Another fact, which is not new, is that many engineering students have a lack of knowledge about what being an engineer really means. The first 3 years of training are particularly intense and hard. The authors of the project suggest that a possible way to improve their perception about the profession is to implement a new kind of course, more enticing and dynamic.

This is one of the proposals of COPEC's engineering education research team: - to embed a course with more interesting activities for students, sooner, in the first year. It is a short-term workshop in order to show students the possibilities of performing as engineers in a global environment - a project developed for a private university in order to increase retention rate among students of engineering courses. It is part of the internationalization of the Engineering Program, due to the need, not only to raise the quality of the program, as well as to start the internationalization process of the university that is the goal.

The main idea is to provide students more dynamic classes, composed by a mix of site visits, lectures, project proposals, a travel period and project presentations, for a period of 3 months, to be carried out on the second semester of the $1^{\text {st }}$ year of the course.

It intends to be a very dynamic experience, providing students a clear view of what it is to be an engineer and what their possibilities for the future are.

The main objective of this project proposal is to provide a sophisticated period to implement integrated environments for teaching/learning systems. The idea is to provide a way to reduce the evasion of engineering courses, showing a glimpse of what it is to be an engineer and to see that there are wide varieties of opportunities worldwide [7].

\section{COPEC - SCIENCE AND EDUCATION RESEARCH ORGANIZATION}

This is an organization of about 18 years of existence, a multi-disciplinary organization, leader on advance science and its application to the development of technology serving society. It started its activities sixteen years ago and since then this organization has made a major contribution to the development of science and education, working to increase the best practices in several research fields.

Integration activities promoted by COPEC provide a qualified coordination and building partnerships, because COPEC is an organization that brings together scientists who share the mission of promoting and developing science, technology and education.

The objectives of COPEC are to promote professionalism, integrity, competency, and education; foster research, improve practice and encourage collaboration in different fields of sciences.

Contents, tools and services provided by COPEC, through courses, publications and consultations, with national and international experts, contribute to the promotion of the professional who wants to be privy of new achievements and service of men to technology.

COPEC enjoys respect and recognition internationally characterized by the open discussion, the free exchange of ideas, respectful debate, and a commitment to rigorous inquiry. Its IIE - International Institute of Education - is a bold and resilient source of innovation in higher education [8].

\section{The Project Design}

The starting point of this project development is the establishment of some actions in phases, in steps that lead to 
the 1 goal to internationalize the Engineering College Programs in a first moment, followed by other programs that the University offers.

\section{TABLE I. THE PHASES}

\begin{tabular}{|c|c|}
\hline Phases & Description \\
\hline 1 -Conception & $\begin{array}{l}\text { At this stage, it is established the estimates of } \\
\text { achievement, dates, allocated resources, } \\
\text { establishment of guidelines and elaboration of } \\
\text { project outlines are discussed. The product of this } \\
\text { stage is the project design }\end{array}$ \\
\hline $2-$ Structuring & $\begin{array}{l}\text { This stage involves all the technical part and } \\
\text { activities necessary for the accomplishment of the } \\
\text { project as: Hiring the operational team; Basic } \\
\text { schedule; Services to be contracted; } \\
\text { Establishment of organization chart; among } \\
\text { others. The product of this step is the entire action } \\
\text { plan and timeline of final activities }\end{array}$ \\
\hline 3 - Execution & $\begin{array}{l}\text { This stage consists of executing the project } \\
\text { according to the action plan and timeline } \\
\text { established between the stakeholders. The product } \\
\text { of this step is the execution of all activities } \\
\text { programmed in the project action plan. }\end{array}$ \\
\hline 4-Closure & $\begin{array}{l}\text { This stage consists in the closing of the project } \\
\text { and the preparation of the reports with } \\
\text { information about the project, with the necessary } \\
\text { documents and documents to render accounts with } \\
\text { the institutions involved in the project. The } \\
\text { product of this step is the final report with the } \\
\text { detailed description of all the actions of the } \\
\text { project. }\end{array}$ \\
\hline
\end{tabular}

TABLE II. THE DEVELOPED ACTIVITIES

\begin{tabular}{|c|ll|}
\hline Terms & \multicolumn{1}{|c|}{ Activities } \\
\hline Short & $\begin{array}{l}\text { Establishment of an International Relations } \\
\text { Office in Europe }\end{array}$ \\
& $\begin{array}{l}\text { Identification of partners to establish } \\
\text { agreements in Europe and the USA } \\
\text { - Scheduling visits to partner universities }\end{array}$ \\
\hline Mid & $\begin{array}{l}\text { Short-term courses outside the country for } \\
\text { undergraduate, graduate and high school } \\
\text { students }\end{array}$ \\
& $\begin{array}{l}\text { Agreements with universities in Europe, the } \\
\text { USA, and Canada }\end{array}$ \\
& $\begin{array}{l}\text { Implementation of top pioneer courses with } \\
\text { unique characteristics } * 1\end{array}$ \\
\hline Long & $\begin{array}{l}\text { Courses offered with double diploma } \\
\text { International Courses }\end{array}$ \\
& $\begin{array}{l}\text { Exchange of students and teachers } \\
\text { Receiving students from outside } * 2 \\
\end{array}$ & Opening of the advanced campus in Europe \\
\hline
\end{tabular}

*1 - The creation and offer of the Cyber Security Course on 3 different levels:

- High school;

- University under graduation;

- Graduation.

- Short international courses for:

- Specialization;

- University Graduation;

- $\quad$ Executive MBA;
- Specialization Course for Engineering Teachers International Engineering Educator.

*2 - Focus on receiving students from CPLP - Community of Portuguese Language Countries members.

About the agreements with other universities, they are the umbrella type with several possibilities such as student and teacher exchange, project development, double enrollment and others stipulated by the colleges involved [9].

It is important to start in Europe for several reasons, as follows:

- the main reason being the visa exemption for citizens;

- the second one, Europe has a very high level of cultural life;

- depending on time of the year, depending on the season, the flying tickets have a more reasonable price.

It is important to go to Canadian and US universities as well. The perspective is to offer:

- 1. Short courses;

- 2. Workshops;

- 3. Joint projects and courses.

The last accomplishment will be the establishment of an advanced Campus of the University in Europe since it is a very important economic block, besides the fact that there is one of the Portuguese Speaking Countries - Portugal, considered one of the most important colonizer countries in the world history.

\section{FACTS ABOUT INTERNATIONALIZATION OF HighER EDUCATION INSTITUTIONS}

It is a fact that there is no right or wrong approach to enter the international educational market. Different circumstances will be prevalent in different countries and for different cultures. In all cases, COPEC's engineering education research team strongly recommends serious reflection and much preparation.

It requires a research on foreign property acquisition, as well as understanding the real estate culture of the chosen country. By taking the courses abroad, universities are replicating their educational models to another set of circumstances, a different place and culture, with a different job market, demands, needs, and expectations.

The question is: is it worth?

And the answer is: absolutely. It is a way to modernize and to keep up with the trends of education for this Century.

If institutions strive for success, there is a fundamental action that is to seek the help of natives and professionals. Becoming international or even global can be one of the most intelligent and profitable moves to improve the quality of the organization, attract new talent and increase its resources, whether human or financial. Otherwise, institutions would be neglecting increasing quality of education, acquiring new 
knowledge and experience and, more importantly, more opportunities for research development [10].

\section{VIII.PERSONAL INTERNATIONALIZATION IMPLICATIONS FOR STUDENTS}

Internationalization is presently seen as an experience of "self-transformation". The contact with international students enables people to see the world from vantage points that reach beyond their own backgrounds - and this allows them to learn about new cultures and countries.

Although for many universities the needs of international students are for monetary reasons too, however, universities will bring longer-term ethical and intellectual considerations to bear on the profit motive.

Successful internationalization of courses and schools means to provide students the opportunity to approach their own cultures, texts, and traditions in different ways and through comparative perspectives. This is a process through which all involved are transformed, and compelled to think differently about their own traditions.

Internationalization is a project with an agenda with intellectual implications. It gives students and scholars the opportunity - and indeed the pressure - to view themselves and their cultures in new ways.

Universities must invest in the economic agenda of internationalization being prepared to embrace its intellectual consequences; otherwise they can embark in a doomed project. And so, for universities to fully internationalize themselves, it is clear that they must look to internationalize their fellow professionals, the teachers and staff first [11].

\section{FinAl CONSIDERATIONS}

For professional careers, many employers state that no skill is more valuable than a foreign language. Many consider English as the "lingua franca". English as a medium of instruction is a prevalent way to offer international higher education as it continues to attract international students. English-taught degree programs continue to develop in many countries worldwide. With a multilingual environment come new challenges and responsibilities. Although the continued prominence of English is uncertain, English continues to play an important role in international higher education as well as in work places [12].

People are considered literate when they speak the mother tongue, English and another foreign language. So the first positive aspect of an experience abroad is the learning of another language besides English.

Another positive aspect of living a period abroad is may be the learning of foreign languages, or getting particularly interested in foreign cultures. So it is likely that sooner or later students will be interested in seeing if the internationalization opportunities of their career would be appropriate for their lives. In academic environments, international travel not only for teachers, but also for students promotes the enrichment of the academic experience. And this attracts more young-people to pursue a career that involves college or university education.

Currently students tend to look for university programs considering other aspects than just the brand, ranking level and reputation of an institution. The trend is to consider the quality and value, including costs, career prospects, and student experiences of the institution, all aspects that have increasingly become important in the student's choice process. The different opportunities that the university can provide is also important and studying abroad is one of them.

It is a fact that students not only from abroad seek out valuable quality experiences: from feeling welcome on campus, to accessible and valuable career advise to student accommodations. Higher education institutions shall continue to focus on creating and nurturing quality student experiences with the aim of retaining national or international students.

The future of higher education will continue to be shaped and changed by the global phenomenon. Along with evolution, comes opportunities and challenges, so, keeping track of higher education trends pushes universities and institutions to go ahead and plan the future of success.

The internationalization project designed by COPEC Engineering Education Research Team comes as an answer for the university, which currently feels this need, fostered by the incentives of governmental agencies, as well as a way to attract more bright students and be at the top ranking. So far, the organized actions that have been put in place are the agreements with universities abroad and a workshop in Europe for a group of students of the Civil Engineering Program. Another aspect is that it is a long-term commitment, which involves steps that lead to the final goal of increasing the quality of programs, be competitive and be among the top ranking of engineering Schools.

\section{REFERENCES}

[1] British Council. Capacity Building \& Internationalization for Higher Education.

https://www.britishcouncil.org.br/atividades/educacao/internacionalizaca o/capacitacao-ensino-superior

[2] Capes. Bolsas e Auxílios Internacional. Available: http://www.capes.gov.br/bolsas-e-auxilios-internacionais

[3] Moskal, Marta. "International Students Pathways Between Open and Closed Borders: Towards a Multi-scalar Approach to Educational Mobility and Labour Market Outcomes." International Migration 55.3 (2017): 126-138.

[4] International Associations of Universities, "Affirming academic values in internationalization of higher education: A call for action”,2012. Retrieved from http://www.aau.org/fr/content/affirming-academicvaluesinternationalization-higher- education-call-action.

[5] Vainio-Mattila, A.,"Internationalizing Curriculum: A new kind of education?", New Directions for Teaching and Learning, vol. 118, pp. 95-103, 2009.http://dx.doi.org/10.1002/t1.356.

[6] Daneva, Maya, Chong Wang, and Patrick Hoener. "What the job market wants from requirements engineers?: an empirical analysis of online job ads from the Netherlands." Proceedings of the 11th ACM/IEEE 
International Symposium on Empirical Software Engineering and Measurement. IEEE Press, 2017.

[7] Brito, Claudio R.; Ciampi, Melany M.;Vasconcelos, Rosa. M.; Amaral, Luis A.; Santos, Henrique D.; Barros, Victor A. "Engineering Course Specially Designed to Face Retention Issue" Proceedings of the 45th SEFI Annual Conference, 2017.

[8] COPEC. Mission. Available: http://copec.eu/menu/mission/

[9] https://www.merriam-webster.com/dictionary/agreement

[10] Hudson, Paul F., and Sarah E. Hinman. "The integration of geography in a curriculum focused to internationalization: an interdisciplinary liberal arts perspective from the Netherlands." Journal of Geography in Higher Education 41.4 (2017): 549-561.

[11] Gould, Rebecca Ruth. Why Internationalization matters in universities. Available: http://theconversation.com/why-internationalisation-mattersin-universities-72533

[12] Amorim, Gabriel B., Finardi, Kyria R. Internacionalização do Ensino superior e linguas estrangeiras: evidências de um estudo de caso nos níveis micro, meso e macro. Avaliação, Campinas; Sorocaba, SP, v.22, n. 03, p. 614-632. http://www.scielo.br/pdf/aval/v22n3/1982-5765-aval22-03-00614.pdf 